\title{
8
}

\section{Gosport Hospital, Euthanasia and Serial Killing}

\author{
Penny Crofts ${ }^{1}$
}

\section{Introduction}

In many jurisdictions euthanasia remains illegal. In part, this is in order to reiterate the sanctity of human life, but also due to fears around changing the central ethos of health institutions and medical practitioners from saving lives to that of causing death. Despite the apparent severity of law, it is recognised that medical practitioners currently provide criminal assistance to patients to die and that this is sometimes without the patients' consent. ${ }^{2}$ There is a certain legal tolerance - in terms of investigations, prosecutions, jury findings and sentencing. ${ }^{3}$ The recent Report of the Gosport Hospital Independent Panel provides a meditation upon homicides without patient consent within the health system. ${ }^{4}$ The Gosport Report found that 456 patients died where opioids were prescribed by Doctor

1 This research was funded by the Australian Government through a Discovery Early Career Researcher Award ('DECRA'), project number DE180100577 'Rethinking Institutional Culpability: Criminal Law, Philosophy and Horror'.

2 Legislative Council, Legal and Social Issues Committee, Parliament of Victoria, Inquiry into End of Life Choices: Final Report (Parliamentary Paper No 174, June 2016) 207, 181-3.

3 Police and prosecutors pursue criminal proceedings where there is evidence to support that cause of action. However, for those who are convicted, sentences tend to be very low in terms of what is possible for these offences. Lorana Bartels and Margaret Otlowski, 'A Right to Die? Euthanasia and the Law in Australia' (2010) 17 Journal of Law and Medicine 532. See also Justins $v$ The Queen (2010) 79 NSWLR 544, which distinguishes between aiding and abetting a suicide and manslaughter.

4 Henceforth, The Report of the Gosport Hospital Independent Panel will be referred to in text as The Gosport Report. 
Barton and then administered by nursing staff without appropriate clinical justification. The Panel also found that there may have been a further 200 such deaths, bringing the overall total to more than 650 patients dying as a consequence of this treatment. ${ }^{5}$ As shown in The Gosport Report, killing patients is a real but occult practice that occurs in the absence of clear and enforced legal norms. There are contradictions within the current legal categories - patients cannot make a free and conscious choice to die but can refuse treatment. Doctors may provide palliative care that has the effect of causing death, on the proviso that this care is given with the intention to relieve suffering and not to shorten life. The absence of established and applied legal norms undermines a clear and debated distinction between unlawful and lawful homicides. This obscure legal framework, coupled with a reluctance to enforce existing laws, provides a veil to homicides occurring within the health system - whether consensual or not.

One of the fears associated with the decriminalisation of euthanasia is that of doctors 'playing God' or worse - killing patients without their consent. There is a developing academic literature of health professionals as serial killers; however the idea remains unusual. Hesketh (2003) has argued that:

The notion of the individual deviance of doctors and other health professionals is so novel that it is sufficient to limit this discussion of the need for a police-health professions' protocol to only those crimes committed by health professionals. That is, this introductory discussion concentrates for the time being on general crime committed by health professionals, which happen to be committed in the course of their employment, not on wider systems failures that might also be regarded by the critical criminologist as crime. ${ }^{6}$

This chapter extends Hesketh's analysis in two ways. First, I take up Hesketh's invitation to extend analysis beyond individual culpability to highlight group culpability and systemic failure in the homicides of patients at Gosport Hospital. Second, I relate serial killer analysis to provide insight into euthanasia - almost a taboo topic. I will consider legal regulation of euthanasia in light of this analysis. This approach is

5 House of Commons, Gosport War Memorial Hospital: The Report of the Gosport Independent Panel (Report, June 2018) ('Gosport War Memorial Hospital Report') graph, 37.

6 Wendy Hesketh, 'Medico-Crime: Time for a Police-Health Professions Protocol' (2003) 76(2)

Police Journal 121, 127. 
suggested in part by the timing of events at Gosport Hospital. The earliest police investigations into Doctor Barton occurred soon after Doctor Harold Shipman was convicted of murdering 15 elderly patients with lethal injections of morphine in January 2000.7 Shipman was arrested for murder on September 1998. A public inquiry was launched in June 2001 to investigate the extent of his crimes, how they went undetected for so long and what could be done to prevent the repeat of the tragedy. Although Shipman was regarded as an isolated example of serial killing by a medical professional, the killings at Gosport Hospital occurred across the same time period. The Gosport Report, published in 2018, revealed that the same concerns about investigation and prevention of mass homicides by the medical profession remained unresolved.

Part one of this chapter highlights vagueness in law and lexicon distinguishing between unlawful homicides and euthanasia reflected and reinforced in The Gosport Report. Part two focuses on the use of the broad category of palliative care to veil unlawful homicides at Gosport Hospital. Part three draws upon the insights of medical practitioner serial killer literature to provide insight into how so many patients were killed at Gosport Hospital over such a long period of time. Part four then considers the implications of serial homicides for the legal regulation of euthanasia.

\section{Lexicon and legal context}

There is a lack of clarity and consistency around the meaning and use of various words in this area, and these definitions are also not necessarily mirrored in law. The word 'euthanasia' dates from the 1640s and is from the Greek 'an easy or happy death' - eu 'good' and thanatos 'death'. In 1869 , the sense of 'legally sanctioned mercy killing' was recorded in English. The literature differentiates between 'voluntary euthanasia' where euthanasia is performed at the request of the person whose life is ended and that person is competent - and non-voluntary euthanasia which is performed without request and/or the person is not competent. ${ }^{8}$ In New South Wales currently, and in England at the time of Gosport

7 Throughout the chapter, I will refer to Doctor Barton using her title, as she was never stripped of her title and retired without being deregistered.

8 For more detail see Lindy Willmott et al, '(Failed) Voluntary Euthanasia Law Reform in Australia: Two Decades of Trends, Models and Politics' (2016) 39 University of New South Wales Law Journal 1, 6 . 
Hospital, neither of these 'types' of euthanasia were legal. Palliative care is described as providing end-of-life care with the intention to relieve pain and not to cause or hasten death, although this may be foreseen. ${ }^{9}$

The literature enunciates a clear distinction between euthanasia and palliative care. ${ }^{10}$ In the majority of countries, including Australia, even where euthanasia remains criminalised, palliative care is legal. The provision of appropriate palliative care is lawful even if it may hasten death:

In the case of PS [palliative care], a physician is generally seen as performing an act that relieves intractable suffering; the outcome of death is not perceived as a physician having 'caused harm' to a patient, but rather as having helped that patient by relieving suffering and distress. ${ }^{11}$

This legal protection arose in response to fears that palliative care might accelerate death, although many argue that palliative care usually does not alter the timing or mechanism of patient's death. ${ }^{12}$ While the law may (ostensibly) be clear in relation to palliative care, in practice the line between palliative care and unlawful slayings is less clear. However, as shown in Gosport Hospital, the line is frequently drawn in favour of characterising care as palliative (and thus legal), rather than as criminal.

The ambiguities in this area arise in part due to a preference for softened and euphemistic language that is framed in terms of health discourse rather than criminal legal discourse. This is reflected in The Gosport Report in quoting witnesses and in the analysis of The Gosport Report itself. Rather than speaking of unlawful homicide (whether murder or manslaughter), The Gosport Report referred to 'end of life care,, ${ }^{13}$ 'end of life pathway', ${ }^{14}$ 'terminal care', 'palliative care', or 'the end'. It was noted that the treatment led patients to 'die sooner rather than later'. ${ }^{15}$

9 Benjamin White and Lindy Willmott, 'How Should Australia Regulate Voluntary Euthanasia and Assisted Suicide?' (2012) 20 Journal of Law and Medicine 410.

10 For an early case see DrAdam's Case: which held that a doctor may do 'all that is proper and necessary to relieve pain, even if the measure ... may incidentally shorten life'. Quoted in Alan W Norrie, Legal Form and Moral Judgment: The Problem of Euthanasia (SSRN Scholarly Paper No ID 1577163, Social Science Research Network, 23 March 2010) <https://papers.ssrn.com/abstract=1577163>.

11 Silvana Barone and Yoram Unguru, 'Should Euthanasia be Considered Iatrogenic?' (2017) 19(8)

American Medical Association Journal of Ethics 802.

12 Ibid.

13 Gosport War Memorial Hospital Report (n 5) 73.

14 Ibid 71.

15 Ibid 61. 
A 2003 review of deaths of patients at Gosport examined Dr Barton's medical records and found that she had a conservative rather than active attitude toward clinical management and preferred palliative care rather than recovery. This finding included 'palliative care' for people who were admitted with fractures for rehabilitation. Very few people in The Gosport Report plainly labelled the actions in Gosport Hospital as homicides, and The Gosport Report itself preferred 'foreshortening of life'. The conclusion of The Gosport Report asserted that 'there was a disregard for human life and a culture of shortening the lives of a large number of patients'. ${ }^{16}$

Throughout The Gosport Report, there are suggestions that the 'shortening' of the lives of patients was a form of euthanasia. For example, in 2001, during one of the many investigations, one of the experts, Professor Donaldson, asked the Commission of Health Investigation 'for reassurance that in the context of an allegation of a "culture of euthanasia" ... the hospital is providing safe care. ${ }^{17}$ In his expert's report to police, which was then given to the General Medical Council (GMC), Professor Gary Ford stated that the 'routine use of opiate and sedative drug infusions without clear indications for their use would raise concerns that a culture of "involuntary euthanasia" existed on the ward'. ${ }^{18}$ A nursing auxiliary at Daedalus Ward, Pauline Spilka told police in 2001 that Daedalus Ward was better termed 'Dead Loss', and described 'the regime of [the nurse] as being geared towards euthanasia'. She asserted that 'euthanasia was practiced by the nursing staff'. ${ }^{19}$ Similarly, an internal police report in 2001 stated that '[T] he allegations being made by the families are effectively that the hospital was guilty of institutionalised euthanasia. ${ }^{20}$ However, the conclusion of The Gosport Report emphasised that the practices at Gosport Hospital were not euthanasia:

It may be tempting to view what happened at the hospital in the context of public debate over end of life care, what a 'good death' is, and assisted dying. That would be a mistake. What happened at the hospital cannot be seen, still less justified, in that context. The patients involved were not admitted for end of life care but

16 Ibid viii.

17 Ibid 87 (emphasis added).

18 Ibid 171 (emphasis added).

19 Ibid 122 (emphasis added).

20 Ibid 134 (emphasis added). 
often for rehabilitation or respite care. The pattern of prescribing and administering drugs was excessive and inappropriate in the ways explained in this Report. ${ }^{21}$

The disagreement over terminology within The Gosport Report reflects the lack of clarity at law and in society about different forms of medical homicide. This labelling is significant because it is confusing, reflects ambiguities in the law, and in turn hampers the possibility of a criminal legal response. ${ }^{22}$ One of the few experts who spoke plainly was Doctor Simon Tanner in 2002 who labelled the actions as 'unlawful killing.' ${ }^{23}$ This use of an accurate label facilitated Tanner recommending action, including a full investigation and corresponding action in terms of clinical governance.

\section{Palliative care and unlawful homicide}

The unlawful homicides at Gosport Hospital were primarily placed within the amorphous and vague category of palliative care. The deaths were caused with a method closely associated with palliative care - the prescription by Dr Barton of drugs used in palliative care, administered by the nursing staff. Dr Barton was a clinical assistant at the hospital for 12 years until she tendered her resignation in April 2000. This was a new post of five sessions a week, worked flexibly to provide 24-hour medical cover. She visited the two wards, Daedalus and Dryad, at 7:30am before arriving at her surgery at 9:00am. Dr Barton would prescribe diamorphine (often in combination with Midazolam and Hyoscine) for patients to be administered by nursing staff using a syringe driver. Dr Barton's method was the same as Shipman's - a swift injection of diamorphine pharmaceutical heroin. ${ }^{24}$ Although these drugs are the kinds of drugs that

\footnotetext{
21 Ibid 319.

22 The difficulties in labelling the offences at Gosport Hospital is in part due to the group element of the offence. The homicides were not committed by only one person acting alone, but by groups of people. While this makes it difficult to point to the murderer at law, it should not be taken to mean that the homicides were lawful. The difficulties of attributing criminal liability to any particular actor, including Dr Barton, is the subject of another paper with David Carter.

23 Gosport War Memorial Hospital Report (n 5) 88.

24 Shipman has been labelled the most prolific serial killer in British history, and arguably the most prolific modern serial killer worldwide, claiming at least 215 victims. John Gunn, 'Dr Harold Frederick Shipman: An Enigma' (2010) 20(3) Criminal Behaviour and Mental Health 190. However, the deaths at Gosport Hospital far exceeded Shipman's murders. The difficulty is that Dr Barton did not act alone, but relied upon the nurses to administer the lethal drugs.
} 
are used in palliative care, the patients for whom Dr Barton prescribed these drugs were not in this situation. Very few patients who received this treatment at Gosport Hospital survived for more than three days. ${ }^{25}$ The underlying cause of death for the majority of these patients was recorded as bronchopneumonia. This treatment breached national and local guidelines at the time - the 'analgesic ladder' - 'start low and go slow' with opioids both in prescription and administration. There was a 'systemic failure to adopt the principles of the analgesic ladder' leading to 'dangerous doses' administered. ${ }^{26}$

The primary way of distinguishing between illegal homicide and palliative care is through the 'intention' of the medical practitioner. To be lawful, palliative care must be provided with the intention to relieve unbearable suffering and not to cause or hasten death, although that death may be foreseen. ${ }^{27}$ This is labelled the doctrine of double effect. In the four Australian states that have enshrined this protection in statute, regard must also be had to other factors such as good medical practice. ${ }^{28}$

The Gosport Report indicates that Dr Barton and the nurses would have foreseen that death upon administration of the drugs was almost certain. For example, despite expressing concerns the nurses continued to administer the drugs 'although the link with the pattern of deaths would have been apparent to them'. Legal principle asserts that where knowledge of an outcome is virtually certain, then this certain knowledge can be equated with intention. ${ }^{29}$ Criminal law asserts that it is interested only in intention and not motive, however criminal law theorists have long highlighted that the question of motive is significant to attributions of culpability. ${ }^{30}$ Motive is the home of moral substance - while intention

25 Gosport War Memorial Hospital Report (n 5) 38.

26 Ibid 20, 316.

27 'What Is Palliative Care?', QUT(Web Page) <https://end-of-life.qut.edu.au/?a=548149\#548149>.

28 For example, under the Consent to Medical Treatment and Palliative Care Act 1995 (SA), a medical practitioner or someone supervised by a medical practitioner who hastens a person's death through medical treatment or care is not liable in civil or criminal law for the person's death if it is consented to, administered without negligence and in good faith with the intention of relieving pain or distress; is provided in accordance with professional standards of palliative care; and the person is in the terminal phase of a terminal illness. See also the Criminal Code Act 1899 (Qld) s 282A; the Criminal Code Act Compilation Act 1913 (WA) s 259; the Medical Treatment (Health Directions) Act 2006 (ACT); and the Powers of Attorney Act 2006 (ACT). See also 'What Is Palliative Care?' (n 27).

29 A classic example is the intention to blow up a plane in order to collect insurance. The primary intention is to collect insurance, however the perpetrator would recognise that death of all on the plane would be virtually certain. Accordingly, intention to kill would be imputed to the perpetrator. 30 Guyora Binder, 'The Rhetoric of Motive and Intent' (2002) 6(1) Buffalo Criminal Law Review 1. 
is a formal question. This is highlighted in relation to palliative care. The issue is not whether the treatment is likely to result in death, but the motive of administering the drugs - was it to alleviate painful symptoms or to cause death? ${ }^{31}$

Given the length of time that had passed between the homicides and The Gosport Report it is difficult to ascertain motive. This is exacerbated by poor and inadequate record keeping, a practice that is not uncommon in the medical profession, and is also a feature in Shipman's murders. ${ }^{32}$ I will consider first Dr Barton's motives and then the motives of the nurses.

There are limited indications in Dr Barton's notes of her motives in prescribing these drugs. Her language is consistent with that of palliative care. Her catchphrases in (poorly recorded) notes include: 'please make comfortable', and even more disturbing 'not obviously in pain please make comfortable'. ${ }^{33}$ The Gosport Report asserts that 'make comfortable' was a 'euphemism for embarking on the pattern of prescribing which would lead to death in almost every case'. ${ }^{34}$ Dr Barton would provide these anticipatory prescriptions when patients were admitted to the hospital - even if it was for respite or rehabilitation. Even more disturbing was a comment she frequently wrote, 'I am happy for nursing staff to confirm death' - for patients admitted for respite or rehabilitation. Doctor Barton defended this by stating:

That was a routine entry I made into the notes of patients who might at some time in the future die on the ward [so that] ... nursing staff ... did not have to bring in an out of hours duty doctor to confirm death ... it did not signify at that time I felt that she was close to death; it was a fairly routine entry in the notes. ${ }^{35}$

The tendency by medical practitioners to present homicide in palliative care terms is so common that researchers have adopted techniques to guard against it. For example, Yorker et al in their analysis of serial murder by healthcare professionals stated:

31 Alan Norrie, Crime, Reason and History: A Critical Introduction to Criminal Law (Cambridge University Press, 2001). Norrie makes this argument specifically in relation to euthanasia arguing that motive animates the discretionary decision not to prosecute: Norrie, Legal Form and Moral Judgment (n 10).

32 Hesketh (n 6) quoting one of the medical expert witnesses who provided an opinion to police in the earlier Shipman investigation.

33 Gosport War Memorial Hospital Report (n 5) 60.

34 Ibid 74.

35 Doctor Barton (2009), quoted in ibid 61. 
We did however include some cases in which the healthcare provider claimed to be engaged in euthanasia as a defense against murder charges. To differentiate between authentic euthanasia and serial murder, we correlated the provider's justification of their actions as euthanasia with patient histories. If a caregiver claimed he or she was engaging in euthanasia, but the patients had been admitted for routine procedures ... and postmortem examinations indicated they died from toxic levels of unauthorized medication, we considered it a case of murder. ${ }^{36}$

No post-mortem examinations took place in relation to the patients who died at Gosport Hospital, however the records indicate Doctor Barton's practice of prescribing palliative care drugs was not based on patient need. ${ }^{37}$ Dr Barton prescribed the drugs to patients who arrived at the ward for respite care and rehabilitation.

News reporting about Gosport Hospital accepts the absence of intention to kill (possibly for fear of a civil suit): 'there is no suggestion that Dr Barton intentionally took lives'. ${ }^{38}$ Like Shakespeare's Iago, there is no apparent motive for her actions, but the consequences were extremely

36 Beatrice Crofts Yorker, Kenneth Kizer and Paula Lampe, 'Serial Murder by Healthcare Professionals' (2006) 51(6) Journal of Forensic Sciences 1362, 1363 (emphasis in original).

37 For example, The Gosport Report notes the Internal Review Panel that was convened to consider complaints by Ann Reeves of the death of her mother Elsie Devine:

Although no guidance at the time or subsequently would support the use of opioids for confusion without pain, the IRP took a different view, and concluded that the clinical response was appropriate. The documents show no basis for the IRP's different view. When the complainant remained dissatisfied with the IRP report, a member of the IRP produced a further report:

She was wandering, agitated, acutely confused, disorientated and frightened. In a frail elderly person this is a very serious medical condition and may be as dangerous as a heart attack but it does not form part of the public perception of a serious or life-threatening illness. For this reason she clearly required a large dose of strong medication, as she was a danger to both herself and people around her.

The Panel can find no basis in the documents or from its wider experience to justify this conclusion, which explicitly condones the use of large doses of diamorphine simply to control symptoms of confusion and agitation. The Panel notes that this conclusion was contrary to all relevant evidence.

Gosport War Memorial Hospital Report (n 5) 76.

38 'Gosport Hospital Deaths: Who Is Jane Barton, the Doctor at the Heart of a Scandal that Claimed Hundreds of Lives?', The Independent (online, 20 June 2018) < https://www.independent.co.uk/news/ uk/home-news/gosport-hospital-deaths-dr-jane-barton-independent-inquiry-gmc-a8408886.html>; same quotation also in Alexandra Topping, 'Profile: Dr Jane Barton, GP and the Gosport Hospital Scandal', The Guardian (online, 21 June 2018) <http://www.theguardian.com/society/2018/jun/20/ profile-dr-jane-barton-gp-gosport-hospital-scandal-gmc-panel-2010>. 
harmful. Her consistent claim is that she practised anticipatory prescribing and wrote 'the nurses can confirm the death' due to lack of resources. Her husband also defended her in these terms:

'Instead of trying to find a new Harold Shipman, it might be more constructive to ask why a part-time GP was looking after 48 beds' the husband told The Sunday Times in 2002. ${ }^{39}$

Her husband asserted that Doctor Barton had been 'overworked and was under a huge amount of pressure'. ${ }^{40}$ Doctor Barton resigned from Gosport Hospital in April 2000 citing concerns over 'staffing levels that do not provide safe and adequate medical cover or appropriate nursing expertise. ${ }^{41}$ Although she claimed to be overworked she had not complained at the time. Upon her resignation the elevated deaths at Gosport Hospital radically dropped. ${ }^{42}$

The absence of any clear motive for Dr Barton is likewise reflected in the homicides by $\mathrm{Dr}$ Shipman. Various motives were suggested for Dr Shipman including that he was playing God, avenging his mother, easing the burdens on NHS and, a more recent suggestion, sexual excitement. ${ }^{43}$ Thunder has researched the motives suggested for homicides in medical facilities - the slaying of the frail, injured or sick of any age to relieve a burden, for profit, for malice or revenge, to pretend to be a saviour, and/or acting out sexual fantasies. ${ }^{44}$ In the absence of any response by Dr Barton, it is unclear why she prescribed the lethal drugs.

Unlike Dr Shipman, Dr Barton delegated authority to the nurses to administer the drugs, to determine the quantity of drugs and to establish death. In criminal law, the nurses who administered the drugs would be

39 'Gosport Hospital Deaths' (n 38); Topping (n 38). Dr Barton started work and had responsibility for the patients in Redclyffe Annex, with approximately 20 beds classified as continuing care. She then had responsibility for an additional 11 beds from the main hospital site until 1993-94 - with a total of 31 beds. From 1993-94 onwards, she was responsible for Dryad and Daedalus wards with a total of 44 beds.

40 'Gosport Hospital Deaths' (n 38).

41 Gosport War Memorial Hospital Report (n 5) 85.

42 Ibid.

43 Shipman refused to co-operate in investigations, refused to speak with professionals, refused a psychiatric defence, and maintained that he was not guilty. He committed suicide in 2004, 'his case remains somewhat of an enigma'. Sarah Hodgkinson, Herschel Prins and Joshua Stuart-Bennett, 'Monsters, Madmen ... and Myths: A Critical Review of the Serial Killing Literature' (2017) 34 Aggression and Violent Behaviour 282, 286.

44 James Thunder, 'Quiet Killings in Medical Facilities: Detection \& Prevention' (2003) 18(3) Issues in Law \& Medicine 211. 
regarded as operating and substantial causes of the deaths of patients. ${ }^{45}$ The nurses were definitely not innocent agents - they knew that patients would die within three days of administration of the drugs. The failure of nursing staff to challenge the drugs and refuse to administer them was in breach of standards that applied at the time: 'the nursing staff also had a responsibility to intervene and challenge the prevailing practice on the wards. ${ }^{46}$ Accordingly, their actions were voluntary acts of independent parties. This would sever the causal nexus between Doctor Barton's original prescriptions and the deaths of patients (although it is arguable that Doctor Barton could be charged as an accessory before the fact or instigator). Given that the nurses knew that the drugs were lethal and contrary to medical practice and the law, why then did they administer the drugs?

One argument is that they were simply obeying doctor's orders. ${ }^{47}$ The impact of the hierarchy was demonstrated in 1988 and 1991 when the nurses expressed concern to hospital management and the Royal College of Nurses about Barton's practice of anticipatory prescription of drugs. ${ }^{48}$ These concerns were shut down by management and not followed up. The Gosport Report notes:

A prevailing culture dominated by the clinical assistant and the consultants which overshadowed any understanding that the nurses could or should exercise their autonomous professional status. ${ }^{49}$

45 Royall v The Queen (1991) 172 CLR 378.

46 Gosport War Memorial Hospital Report (n 5) 45.

47 Stanley Milgram, Obedience to Authority: An Experimental View (Harper \& Row, 1974).

48 In Shipman's case, no-one complained or raised concerns about a single death until 1998, by which time he had killed more than 200 patients over a period of 20 years. Eventually, two funeral directors became suspicious about the circumstances of the deaths. Prior to 1998 two nonprofessionals had concerns - but were advised by friends and family to do nothing - especially due to fear of being sued for defamation. A taxi driver of elderly patients and a warden of sheltered accommodation where several of Shipman's patients lived and died were wracked by guilt and regret. They believed that because they were not professionals if they had tried to make a report it would have fallen on deaf ears. Unlike Doctor Barton, Shipman was unusually isolated. Doctors at the practice adjacent to Shipman's became suspicious around the same time as the funeral directors, when they noticed they were signing an abnormally large number of cremation certificates for him. The doctors reported their joint concerns to the coroner. The police, to whom the coroner passed The Gosport Report, made a very superficial job of the investigation and concluded that there was nothing amiss. The detective inspector in charge thought the concerns were unfounded from the start because Shipman was well respected. His mind was not really open to the possibility that what was being suggested might be true.

See, Janet Smith, 'Public Interest Responsibilities of Professionals: Lecture Given for Public Concern at Work on 13 October 2005' (2006) 46(2) Medicine, Science and the Law 93.

49 Gosport War Memorial Hospital Report (n 5) 49. 
A nurse stated that despite 'considerable disquiet amongst ... staff' you can only be told so many times that you don't know what you are talking about'..$^{50}$ Nurses were concerned 'they would be sacked or moved ... wouldn't be supported ... would be named a trouble maker'. ${ }^{51}$

The Panel found a picture of care which fell well below the expected standards of nursing practice at that time. It is a picture which demonstrates a lack of care for individuals' assessed needs, as well as a lack of challenge to the prevailing practice at the hospital. It also illustrates the bravery of the nurses who raised concerns in $1991 . .^{52}$

This reflects the insights of medical research. There has been a great deal of literature about the ways in which medical hierarchies undermine any possibility of nurses challenging doctors. ${ }^{53}$

There is, however, a darker motive for the nurses administering drugs - the removal of 'troublesome' patients. ${ }^{54}$ The Gosport Report notes that 'opioids already prescribed in this way could be used as an inappropriate response to a patient's agitation or challenging behaviour'. ${ }^{55}$ The Gosport Report suggests that patients may not have been given food or water, which may have led to 'troublesome' behaviour. The lethal drugs were administered to patients with dementia or incontinence, or who were just plain thirsty or hungry. Nurse Spilka claimed that she had argued with Nurse Marion Berry about administering drugs to a patient. The patient was lazy and quite tearful. Nurse Berry said if he wasn't careful he would 'talk himself onto a syringe driver'. Accordingly, staff had foresight that administration of the drugs would lead to death and their motive may have been to reduce workload or get rid of 'irritating' patients.

The idea that nurses were killing 'troublesome' patients reflects and reinforces fears of legalising euthanasia. That is, it is believed that presently the criminalisation of euthanasia retains the sanctity of human life, a protection against the utilitarian rationale of the health system, which is that limited resources and time must be allocated in a way that is

50 Ibid 41. For a sociological analysis of literal denial of atrocities by institutions see Stanley Cohen, States of Denial: Knowing About Atrocities and Suffering (Polity Press, 2001).

51 Gosport War Memorial Hospital Report (n 5) 91.

52 Ibid 48.

53 Marie M Bismark et al, 'Mandatory Reports of Concerns about the Health, Performance and Conduct of Health Practitioners' (2014) 201(7) Medical Journal of Australia 399.

54 Gosport War Memorial Hospital Report (n 5) 85.

55 Ibid 29. 
most beneficial to the most people. According to this approach, it is more rational to kill than to care for problematic, high-maintenance patients who are expensive in an overcrowded and overworked health system. ${ }^{56} \mathrm{It}$ is feared that legalising euthanasia could lead to dystopian futures and social inequalities. ${ }^{57}$ However, the killings in Gosport Hospital epitomised fears of dystopian futures and took place while euthanasia was criminal. The killings at Gosport Hospital were facilitated in part by the amorphous category of palliative care and the central role of motive in differentiating between whether a 'treatment' is legal or criminal. As Gosport Hospital showed, a doctor's intentions when providing certain treatments are easy to obscure or can be ambiguous. The same act can be done, namely hastening a patient's death, with radically different intentions. ${ }^{58}$ Serial killers are able to take advantage of the ambiguous legal distinction between palliative care and unlawful homicide to reduce the likelihood of being detected and stopped.

\section{Medical practitioners as serial killers}

The notion of considering the vagueness of law about euthanasia and palliative care through the prism of serial killing may seem farfetched, especially as it is believed that killings like those at Gosport Hospital and by Dr Shipman are isolated and rare. However, there are numerous examples internationally of 'caregiver associated killing', ${ }^{59}$ and increasing

56 Examples of motives that have been prosecuted and criminalised include Megan Haines, a nurse in an elderly nursing home, who was found guilty of two counts of murder in NSW in 2016. She murdered the residents several days after they made a complaint about the standard and quality of care she delivered. Haines was sentenced to 36 years imprisonment. Garling J: 'Her conduct was deliberate and calculating. It was a gross breach of trust and a flagrant abuse of her power ... She clearly abused that position of trust. I consider this to be a significant aggravating factor.' ( $R v$ Haines [2016] NSWSC 1824). Dr Crickitt killed his wife with a lethal dose of insulin. The court was satisfied that he did this because he increasingly disliked his wife and was infatuated with another woman ( $R v$ Crickitt [2016] NSWSC 1738). Barbara Salisbury, a nurse on a geriatric ward in Crew was convicted of the attempted murder of two patients and acquitted with regard to two more. She was obsessed with unblocking beds in the ward. The judge said that she had broken her duty of care and abused her position of trust 'by attempting to hasten death'. She also administered diamorphine to patients. A question in the case was whether she was 'easing the passing' of patients or breaching her duty of trust (Helen Carter, 'Nurse Gets Five Years for Seeking to Kill Two Patients', The Guardian (online, 19 June 2004) <https://www.theguardian.com/society/2004/jun/19/health.uknews>).

57 Norrie (n 10).

58 White and Willmott (n 9); Lindy Willmott, Benjamin White and S Then, "Withholding and Withdrawing Life-Sustaining Medical Treatment' in Benjamin White, F McDonald and Lindy Willmott (eds), Health Law in Australia (Thomson-Reuters, 2010) [13.280-13.290].

59 Crofts Yorker, Kizer and Lampe (n 36). 
recognition that serial homicides by doctors are not unique to people such as Dr Shipman (and Dr Barton). ${ }^{60}$ In fact, Kinnell has argued that medicine has arguably thrown up more serial killers than all the other professions together, with nursing a close second. ${ }^{61}$ There is a tendency to avoid thinking about homicides by medical practitioners. It challenges our feelings of safety and the trusted position of doctors in society. This tendency to avoid thinking of homicidal medical practitioners is reflected in the history of investigations and in The Gosport Report itself. Through the long history of intermittent queries raised by staff and family members, investigations by police, the GMC, and internal and external medical and nursing committees regarding the 'treatment' at Gosport Hospital, it was almost unthinkable to consider the deaths as unlawful homicides. This is reflected in The Gosport Report's preference for the euphemistic phrase, noted above, of 'shortening of life' rather than the more accurate labels of 'killing', 'slaying' or 'unlawful homicide'.

In part, the relative ignorance about medical practitioners as serial killers is because they do not reflect popular culture understandings of serial killers. Hodgkinson et al argue that cases such as Shipman challenge our belief 'that we can readily identify a serial killer, that they are not people in positions of trust, or people we know, and that they can be easily apprehended by law enforcement'. ${ }^{62}$ Gosport Hospital exacerbates this discomfort - because it was not the act of one isolated, malevolent individual but included other staff - whether actively administering lethal drugs and/or failing to prevent the homicides over the many years. Academic analysis highlights why doctors are the most prolific serial killers. Doctors are trusted, hence the phrase 'doctor knows best'. They have access to vulnerable and unwell people. ${ }^{63}$ They have no difficulties in disposing of bodies. The treatment by Dr Barton was largely unquestioned by the majority of family members, consulting physicians, the GMC, police, coroners and the Council of Nurses. Systems in place to protect vulnerable patients failed abysmally. On the rare occasions when Doctor Barton was questioned by staff and/or family members, the questions were undermined by management and police, who suggested that they were

60 Thunder (n 44).

61 Herbert Kinnell, 'Serial Homicide by Doctors: Shipman in Perspective' (2000) 321(7276) BMJ 1594. See also Clare Dyer, 'Police Investigate Deaths of Terminally Ill Patients' (2000) 321(7267) BMJ 981; Katherine Ramsland, Inside the Minds of Healthcare Serial Killers: Why They kill (Praeger, 1st ed, 2007); Crofts Yorker, Kizer and Lampe (n 36).

62 Hodgkinson, Prins and Stuart-Bennett (n 43).

63 Alec Samuels, 'Editorial: Doctor Harold Shipman' (2000) 68(2) Medico-Legal Journal 37, 37. 
not coping with their grief or were being unprofessional. When family members (nursing staff and eventually police) questioned 'treatments', the hospital responded in a hierarchical fashion that protected Dr Barton.

Hodgkinson et al argue that the dominant approach to the study of multiple killings, advanced by the FBI as well as other sources of highly influential information within the realms of mass media, supports an understanding and response that is principally fixed at the individual level. ${ }^{64}$ This approach focuses on the killer's disposition or character, but fails to consider the 'wider social, cultural and historical contexts that may generate, shape and facilitate such behaviours, and that problematises the reductionist "traditionalist" approach'. ${ }^{65}$ That is, there is a tendency to regard serial killers as acontextual and ahistorical. In contrast, Hodgkinson et al have argued that it is necessary to place these crimes within their own particular context. They have focused on the regard and value of the victim group, arguing that serial killers operate within the context of cultures of denigration and marginalisation of particular social groupings lacking protection and becoming vulnerable to predation. ${ }^{66}$

Those who want to kill repeatedly can only achieve this objective when the social structure in which they operate allows them to do so by placing value on one group to the detriment of others. ${ }^{67}$

The elderly patients killed at Gosport Hospital (and by Dr Shipman) fit within the category of denigrated and marginalised. ${ }^{68}$ There is an insidious presumption that old people will die soon anyway, with the consequence that abuse, neglect and consequent suffering is inadequately or not responded to at all in terms of detection, treatment, intervention and prosecution. ${ }^{69}$

The analysis of the context of serial killings can be extended to the regard of the medical profession. Medical homicides are less likely to be investigated and prosecuted because of the hierarchy both within the medical profession and outside. I have already noted that nurses were

64 Hodgkinson, Prins and Stuart-Bennett (n 43).

65 Ibid 288.

66 Ibid.

67 David Wilson, Serial Killers: Hunting Britons and Their Victims 1960 to 2006 (Waterside Press, 2007) 23.

68 Concerns about the cultural denigration of the elderly and their vulnerability to predation is reflected in the current Australian Royal Commission into Aged Care.

69 Thunder (n 44). 
actively discouraged from reporting their concerns about 'the treatment' at Gosport Hospital. This absence of reporting extends to the peers of doctors. Doctors are unlikely to report wrongdoing or incompetence because of fears of reprisals and detriments of various kinds. ${ }^{70}$ Likewise, Rosenthal has noted that the profession will tend to cover up incompetence and misconduct committed by individuals. ${ }^{71}$ This may in part be a form of institutional narcissism, with the aim of protecting the reputation of the medical profession generally. But it may also be due to a perception of the need to protect the health profession from the intervention of the criminal legal system. ${ }^{72}$ The Gosport Report is clear that the doctors 'supervising' Dr Barton should have been aware of and challenged Dr Barton's prescription of lethal drugs. However, due to the passing of time it is unclear what the doctors did or did not know. The only thing that is clear is that they maintained professional solidarity and did not report the chronic overprescription and administration of lethal drugs.

The hierarchy extends beyond those within the medical profession to how the criminal legal system relates with the medical profession - both powerful professions. The medical profession is treated as a special case in criminal law. Medical professionals are able to touch and cut bodies, handle and administer drugs, and document as lawful acts that, outside the medical context, are regarded as the greatest of crimes. ${ }^{73}$ The police are dependent on the medical profession to explain treatments and reasonable practices. The hierarchical relationship was shown in Gosport Hospital with police asking and then accepting Doctor Barton's reassurances that this was appropriate treatment and that using diamorphine is not any form of euthanasia. ${ }^{74}$ Police then also kept Gosport Hospital informed and even assisted the hospital in writing a press release about investigations, ${ }^{75}$ despite recognition that the institution itself could

70 Smith (n 48). Smith compares the tribal nature of the medical profession to that of the legal profession. High standards are required for admission to the profession, but once admitted, the professional was within a society of like-minded people who understood each other and shared common interests. Smith refers to the example of the Bristol Royal Infirmity case, in which Dr Steve Bolsin had tried to draw attention to the problem in the paediatric cardiac surgery department but no-one listened for a long time and he was treated as an outcast.

71 Marilynn M Rosenthal, The Incompetent Doctor Behind Closed Doors (Open University Press, 1995).

72 David J Carter, 'HIV Transmission, Public Health Detention and the Recalcitrant Subject of Discipline: Kuoth, Lam $v$ R and the Co-Constitution of Public Health and Criminal Law' (2016) 25(2) Griffith Law Review 172.

73 Hesketh (n 6).

74 Gosport War Memorial Hospital Report (n 5) 107.

75 Ibid 116. 
potentially be liable for medical negligence. There is no clear protocol for police liaison with health authorities to prevent, detect or investigate medico-crime. ${ }^{76} \mathrm{It}$ is believed that the medical profession will police itself, a 'usurpation of the police role'..$^{77}$ Professional bodies such as the GMC and Nursing and Midwifery Council have a 'monopoly on the technical knowledge of medicine and, because of the intricacies of the unique medical environment, it can be expected to act responsibly. ${ }^{78}$ They are responsible for entry into the professions, monitoring standards and disciplining members for misconduct. However, in the case of Gosport Hospital none of these professional bodies fulfilled their policing roles. No-one was punished. No-one lost their jobs or registration. Specifically, Dr Barton has never been charged with any criminal offences. In addition, she kept her medical license until voluntary retirement many years later. ${ }^{79}$

The analysis of the context of serial killings at Gosport Hospital also extends to resource implications. A constant theme throughout The Gosport Report is that of limited resources. This was not only in terms of the capacity to treat patients in the hospital system (argued by Dr Barton), but also to the ability of regulatory bodies to investigate and prosecute. For example, the police and coroner eventually recognised that there may have been many more homicides at Gosport Hospital, but lacked the resources to pursue this further - both in terms of individual and institutional culpability.

\section{Safeguards against homicides}

The serial killer literature detailed above highlights that we should analyse not only the killer, but also the context in which the killings occur. The killings at Gosport Hospital occurred at an institution that was perceived to be safe and trusted, against victims who were vulnerable and elderly, in a professional hierarchy that is expected to police itself and is unlikely to report malfeasance. The killings occurred in the context of a systemic failure to prevent serial homicides by the medical profession. There are many safeguards that could be imposed to protect against

\footnotetext{
76 Hesketh (n 6).

77 Ibid 124.

78 Ibid 122.

79 'Gosport Hospital Deaths' (n 38).
} 
unlawful homicides of the kind that occurred at Gosport Hospital. ${ }^{80}$ This includes tracking the rate of death for individual doctors, wards and hospitals. Another simple safeguard would be to monitor drug prescribing habits of doctors. The Gosport Report provides stark graphs of rates of death and prescription of which even a cursory monitoring should have sounded alarm bells. Doctors are already required to keep notes of patient treatment but many do not do so, including serial killers such as Doctors Barton and Shipman, who rely upon the brevity of records to veil malfeasance. Doctors should be required to keep full computer records that are open to confidential audits. There should be procedures in place that encourage and respond appropriately to concerns and suspicions by staff - including nurses.

The Gosport Report also highlights that legal regulation should specify the ways in which family members are communicated with and how their concerns are treated. Note that much of the literature in this area is focused on protection of the elderly from their family and undue influence. ${ }^{81}$ However, the homicides at Gosport Hospital highlights the other side - how family members attempted to protect their family from harmful treatments. Families were marginalised by professional staff at Gosport Hospital. Conversations were 'often brief, cursory and dismissive'. For example, a son reported that:

[w] hen he was told his mother was unwell and 'we would like your permission to administer the necessary drugs to assist her through to the end.' Naturally I was very distressed by this, and tearful, and expressed my amazement that I was being asked to sanction what appeared to be euthanasia. When we left the meeting room, [the doctor] commented to the nursing staff 'we've got another weeper here'. ${ }^{82}$

Concerns about treatment, hydration and nutrition were treated as sadness about death, rather than recognition of a general problem with the 'treatment', despite management handling the same complaints over and over again. Family members who reported concerns outside the institution were treated in the same manner. Police responded to Mrs MacKenzie, the woman who persevered for decades by continuing

80 Crofts Yorker, Kizer and Lampe (n 36).

81 Anne PF Wand et al, 'The Nexus Between Elder Abuse, Suicide, and Assisted Dying: The Importance of Relational Autonomy and Undue Influence' (2018) 18 Macquarie Law Journal 79.

82 Gosport War Memorial Hospital Report (n 5) 74. 
to raise questions about the death of her mother, by classifying her as a 'trouble maker'. ${ }^{83}$ Accordingly, reforms to protect against serial killings by medical professionals should include the development of procedures to encourage and respond appropriately to concerns by family members.

An additional safeguard against unlawful homicides would be to clarify the law. Currently, medical professionals can hide homicides behind the vague and amorphous category of 'palliative care', confident in their protection within the medical hierarchy. Part of the clarification of law would include decriminalising euthanasia. Questions have been raised about whether unlawful homicides by medical practitioners can be relied upon to justify legalisation of euthanasia. For example, Keown has argued that the experience internationally is that legalisation does nothing to reduce the opportunity for abuse of the law. Keown asks, if medical practitioners already break the law why would this change if it was legalised ${ }^{84} \mathrm{He}$ asserts that far from decreasing homicides, the practice is likely to increase if euthanasia is legalised. However, international quantitative studies have found the contrary. The Queensland University of Technology (QUT) summarised deaths due to voluntary euthanasia, assisted suicide and involuntary euthanasia since 1990 in the Netherlands and showed a decrease in life-terminating acts without explicit request of the patient, while voluntary euthanasia and assisted suicide stayed stable. ${ }^{85}$ In other words, slayings without the consent of the victim decreased in a framework of legalised euthanasia. Similarly, Kuhse et al found that Australia had a higher rate of intentional ending of life without the patient's request than the Netherlands where euthanasia is openly practiced. The prohibition of euthanasia has not prevented doctors from practising euthanasia or making medical end-of-life decisions explicitly intended to hasten the patient's death without the patient's request. ${ }^{86}$ What it does mean is that doctors are making these decisions in the absence of a clear legal framework of the standards required for lawful homicides in the health system. The experience in Belgium suggests that legalisation would bring with it its own regulatory issues and concerns

83 Ibid 107.

84 John Keown, “Voluntary Assisted Dying” in Australia: The Victorian Parliamentary Committee's Tenuous Case for Legalization’ (2018) 33(1) Issues in Law \& Medicine 55.

85 Willmott, White and Then (n 58).

86 Helga Kuhse et al, 'End-of-Life Decisions in Australian Medical Practice' (1997) 166(4) Medical Journal of Australia 191. 
surrounding unethical medical practices. ${ }^{87}$ The law reform process would include debates about eligibility criteria (eg only terminally ill, adults with capacity, broader cohort?), what safeguards would be constructed (eg involving only the treating doctor or other specialists?) and the kinds of state oversight (eg independent review of each death? Prospective or retrospective?). ${ }^{88}$ Legalisation would include safeguards and standards that are currently absent in a criminalised environment. ${ }^{89}$

\section{Conclusion}

Some of the worst fears about euthanasia are doctors and/or the health system killing expensive and/or troublesome patients in a time of limited resources. In those jurisdictions that criminalise euthanasia, a decision has been made to communicate that killing of human beings is wrong and the hope that criminal law will provide a deterrence to homicide. However, this chapter has argued that doctors and nurses are already covertly involved in making end-of-life decisions..$^{90}$ Voluntary euthanasia and assisted suicide occur despite being unlawful. ${ }^{91}$ Worse, as events at Gosport Hospital show, decisions are made that would not be consistent with any modern form of legalised euthanasia. ${ }^{92}$ Gosport Hospital involved the non-consensual, institutional slaying of patients. Although serial killer literature appears to be an extreme case through which to consider practices of euthanasia,

87 Tinne Smets et al 'Reporting Euthanasia in Medical Practice in Flanders, Belgium: Cross Sectional Analysis of Reported and Unreported Cases' (2010) 341 BMJ c5174.

88 Willmott, White and Then (n 58).

89 For example, the Voluntary Assisted Dying Act 2017 (Vic) requires a person to have lived in Victoria for a minimum of one year; be over the age of 18 ; have decision-making capacity in relation to voluntary assisted dying; to have a condition that is incurable, advanced, progressive and will cause death; to have six months to live; and experience suffering that cannot be relieved in a manner perceived as tolerable to the individual. There must be two independent medical assessments and a written declaration from the person requesting assisted dying. There are also safeguards to protect vulnerable people from coercion and abuse. Requests will be subject to a dedicated board. A person whose primary reason for requesting assisted dying is a mental illness or a disability alone is ineligible. Keown has pointed to ethical questions within this legislation. Why should assisted dying be limited to only those who will die within the year? Why also is it only available for those sufficiently competent to request it? He notes that in Belgium and the Netherlands there has been 'bracket creep'; see Keown (n 84).

90 See Diaconescu, who notes cases such as Dr J Kevorkian's charge of murder for carrying out euthanasia in 130 cases. Amelia Mihaela Diaconescu, 'Euthanasia' (2012) 4(2) Contemporary Readings in Law and Social Justice 474.

91 Charles D Douglas et al, 'The Intention to Hasten Death: A Survey of Attitudes and Practices of Surgeons in Australia' (2001) 175(10) Medical Journal of Australia 511. Willmott, White and Then (n 57).

92 I am leaving aside euthanasia in Nazi Germany. Involuntary euthanasia was practised on tens of thousands of mentally sick people in Germany between the years of 1933 and 1945. Diaconescu (n 90). 
it highlights that medical practitioners are able to kill behind the veil of ambiguous and rarely enforced laws and also demonstrates the need to implement and maintain effective safeguards. The medical practitioner serial killing literature challenges our preconceptions of serial killers and the medical profession. These slayings by the medical profession are not anomalous. Ultimately, the events at Gosport Hospital raise questions about the medical professional monopoly on regulation in relation to medico-crime. ${ }^{93}$ Legal regulation of euthanasia will not solve all problems in relation to end-of-life decisions in the health system, but it will go some way towards addressing some of the ways in which medical professionals can take advantage of their roles to kill patients. It will give an opportunity to articulate and justify reasons for killing, rather than leaving it to covert, private decisions by medical professionals.

\section{Bibliography}

\section{A Articles/books/reports}

Barone, Silvana and Yoram Unguru, 'Should Euthanasia Be Considered Iatrogenic?' (2017) 19(8) American Medical Association Journal of Ethics 802 doi.org/10.1001/journalofethics.2017.19.8.msoc1-1708

Bartels, Lorana and Margaret Otlowski, 'A Right to Die? Euthanasia and the Law in Australia' (2010) 17 Journal of Law and Medicine 532

Binder, Guyora, 'The Rhetoric of Motive and Intent' (2002) 6(1) Buffalo Criminal Law Review 1 doi.org/10.1525/nclr.2002.6.1.1

Bismark, Marie M et al, 'Mandatory Reports of Concerns about the Health, Performance and Conduct of Health Practitioners' (2014) 201(7) Medical Journal of Australia 399 doi.org/10.5694/mja14.00210

Carter, David J, 'HIV Transmission, Public Health Detention and the Recalcitrant Subject of Discipline: Kuoth, Lam $v R$ and the Co-Constitution of Public Health and Criminal Law' (2016) 25(2) Griffith Law Review 172 doi.org/ $10.1080 / 10383441.2016 .1238563$

Cohen, Stanley, States of Denial: Knowing About Atrocities and Suffering (Polity Press, 2001) 
Diaconescu, Amelia Mihaela, 'Euthanasia' (2012) 4(2) Contemporary Readings in Law and Social Justice 474

Douglas, Charles D et al, 'The Intention to Hasten Death: A Survey of Attitudes and Practices of Surgeons in Australia' (2001) 175(10) Medical Journal of Australia 511 doi.org/10.5694/j.1326-5377.2001.tb143704.x

Dyer, Clare, 'Police Investigate Deaths of Terminally Ill Patients' (2000) 321(7267) BMJ 981

Gunn, John, 'Dr Harold Frederick Shipman: An Enigma' (2010) 20(3) Criminal Behaviour and Mental Health 190 doi.org/10.1002/cbm.768

Hesketh, Wendy, 'Medico-Crime: Time for a Police-Health Professions Protocol?' (2003) 76(2) The Police Journal 121 doi.org/10.1177/0032258X0307600203

Hodgkinson, Sarah, Herschel Prins and Joshua Stuart-Bennett, 'Monsters, Madmen ... and Myths: A Critical Review of the Serial Killing Literature' (2017) 34 Aggression and Violent Behavior 282 doi.org/10.1016/j.avb.2016. 11.006

House of Commons, Gosport War Memorial Hospital: The Report of the Gosport Independent Panel (Report, June 2018)

Keown, John, "Voluntary Assisted Dying in Australia": The Victorian Parliamentary Committee's Tenuous Case for Legalization' (2018) 33(1) Issues in Law \& Medicine 55

Kinnell, Herbert G, 'Serial Homicide by Doctors: Shipman in Perspective' (2000) 321(7276) BMJ 1594 doi.org/10.1136/bmj.321.7276.1594

Kuhse, Helga et al, 'End-of-Life Decisions in Australian Medical Practice' (1997) 166(4) Medical Journal of Australia 191 doi.org/10.5694/j.1326-5377.1997. tb140074.x

Legislative Council, Legal and Social Issues Committee, Parliament of Victoria, Inquiry into End of Life Choices: Final Report (Parliamentary Paper No 174, June 2016)

Milgram, Stanley, Obedience to Authority: An Experimental View (Harper \& Row, 1974)

Norrie, Alan, Crime, Reason and History: A Critical Introduction to Criminal Law (Cambridge University Press, 2001) 
Norrie, Alan W, Legal Form and Moral Judgment: The Problem of Euthanasia (SSRN Scholarly Paper No ID 1577163, Social Science Research Network, 23 March 2010) <https://papers.ssrn.com/abstract=1577163> doi.org/ $10.2139 /$ ssrn. 1577163

Ramsland, Katherine, Inside the Minds of Healthcare Serial Killers: Why They Kill (Praeger, 1st ed, 2007)

Rosenthal, Marilynn M, The Incompetent Doctor: Behind Closed Doors (Open University Press, 1995)

Samuels, Alec, 'Editorial: Doctor Harold Shipman' (2000) 68(2) Medico-Legal Journal 37 doi.org/10.1258/rsmmlj.68.2.37

Smets, Tinne et al, 'Reporting of Euthanasia in Medical Practice in Flanders, Belgium: Cross Sectional Analysis of Reported and Unreported Cases' (2010) 341 BMJ c5174 doi.org/10.1136/bmj.c5174

Smith, Janet, 'Public Interest Responsibilities of Professionals: Lecture Given for Public Concern at Work on 13 October 2005' (2006) 46(2) Medicine, Science and the Law 93 doi.org/10.1258/rsmmsl.46.2.93

Thunder, James M, 'Quiet Killings in Medical Facilities: Detection \& Prevention' (2003) 18(3) Issues in Law \& Medicine 211

Wand, Anne PF et al, 'The Nexus between Elder Abuse, Suicide, and Assisted Dying: The Importance of Relational Autonomy and Undue Influence' (2018) 18 Macquarie Law Journal 79

White, Ben and Lindy Willmott, 'How Should Australia Regulate Voluntary Euthanasia and Assisted Suicide?' (2012) 20(2) Journal of Law and Medicine 410

Willmott, Lindy et al, '(Failed) Voluntary Euthanasia Law Reform in Australia: Two Decades of Trends, Models and Politics' (2016) 39 University of New South Wales Law Journal 1

Willmott, Lindy, Benjamin White and S Then, 'Withholding and Withdrawing Life-Sustaining Medical Treatment' in Benjamin White, F McDonald and Lindy Willmott (eds), Health Law in Australia (Thomson-Reuters, 2010)

Wilson, David, Serial Killers: Hunting Britons and Their Victims 1960 to 2006 (Waterside Press, 2007)

Yorker, Beatrice Crofts et al, 'Serial Murder by Healthcare Professionals' (2006) 51(6) Journal of Forensic Sciences 1362 doi.org/10.1111/j.15564029.2006.00273.x 
VOLUNTARY ASSISTED DYING

\section{B Cases}

Justins v The Queen (2010) 79 NSWLR 544

$R v$ Crickitt [2016] NSWSC 1738

$R v$ Haines [2016] NSWSC 1824

Royall $v$ The Queen (1991) 172 CLR 378

\section{Legislation}

Consent to Medical Treatment and Palliative Care Act 1995 (SA)

Criminal Code Act 1899 (Qld)

Criminal Code Act Compilation Act 1913 (WA)

Medical Treatment (Health Directions) Act 2006 (ACT)

Powers of Attorney Act 2006 (ACT)

Voluntary Assisted Dying Act 2017 (Vic)

\section{Other}

Carter, Helen, 'Nurse Gets Five Years for Seeking to Kill Two Patients', The Guardian (online, 19 June 2004) <https://www.theguardian.com/ society/2004/jun/19/health.uknews>

'Gosport Hospital Deaths: Who Is Jane Barton, the Doctor at the Heart of a Scandal that Claimed Hundreds of Lives?', The Independent (online, 20 June 2018) <https://www.independent.co.uk/news/uk/home-news/gosport-hospitaldeaths-dr-jane-barton-independent-inquiry-gmc-a8408886.html> Topping, Alexandra, 'Profile: Dr Jane Barton, GP and the Gosport Hospital Scandal', The Guardian (online, 21 June 2018) <http://www.theguardian.com/society/2018/ jun/20/profile-dr-jane-barton-gp-gosport-hospital-scandal-gmc-panel-2010>

'What Is Palliative Care?', QUT (Web Page) <https://end-of-life.qut.edu.au/?a= 548149\#548149> 
This text is taken from Voluntary Assisted Dying: Law? Health? Justice?, edited by Daniel J Fleming and David J Carter, published 2022 by ANU Press, The Australian National University, Canberra, Australia.

doi.org/10.22459/VAD.2022.08 